Proceedings of the 16th Czech and Slovak Conference on Magnetism, Košice, Slovakia, June 13-17, 2016

\title{
FeSiBAlNiMo High Entropy Alloy Prepared by Mechanical Alloying
}

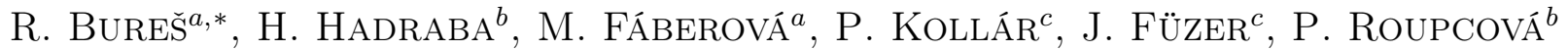 AND M. STREČKOVÁ ${ }^{a}$}

${ }^{a}$ Institute of Materials Research, Slovak Academy of Sciences, Watsonova 47, 04001 Košice, Slovak Republic ${ }^{b}$ Institute of Physics of Materials, Academy of Sciences of Czech Republic, Žižkova 22, 616 62 Brno, Czech Republic

${ }^{c}$ Institute of Physics, Faculty of Science, P.J. Safarik University in Košice,

Park Angelinum 9, 04154 Košice, Slovak Republic

\begin{abstract}
High-entropy alloys have attracted increasing attentions because of their unique compositions, microstructures, and adjustable mechanical and functional properties. In this work, mechanical and magnetic properties of the FeSiBAlNiMo high-entropy alloy were studied in heat-treated conditions. Influence of temperature and time of sintering was investigated. The lowest coercivity $H_{c}=370 \mathrm{~A} / \mathrm{m}$ was reached at sintering temperature $580{ }^{\circ} \mathrm{C}$, during $20 \mathrm{~min}$ in $\mathrm{Ar} / 10 \mathrm{H}_{2}$ atmosphere. Resistivity decreases from $R=0.006 \Omega \mathrm{cm}$ at $580^{\circ} \mathrm{C}$ of sintering temperature to $R=0.0004 \Omega \mathrm{cm}$ at temperature $1100^{\circ} \mathrm{C}$. Transverse rupture strength TRS $=340 \mathrm{MPa}$ as well as the Young modulus $E=87 \mathrm{GPa}$ were much higher in the case of sintering at $1100^{\circ} \mathrm{C}$ in comparison to $\mathrm{TRS}=5 \mathrm{MPa}$ and $E=7.5 \mathrm{GPa}$ at sintering temperature $580^{\circ} \mathrm{C}$. Low temperature consolidation made possible to structure recovery and stress relief of amorphous-nanocrystalline structure. Higher temperature above $1100{ }^{\circ} \mathrm{C}$ induced sintering processes and formation of complex borides.
\end{abstract}

DOI: 10.12693/APhysPolA.131.771

PACS/topics: $81.05 .-\mathrm{t}, 75.50 . \mathrm{Tt}, 75.50 . \mathrm{Kj}, 62.20 .-\mathrm{x}$

\section{Introduction}

Traditional strategy of physical metallurgy is based on one principal element as matrix. There are iron based alloys, nickel based super alloys etc., as well as metal matrix composites. Novel alloy design concept is based on multiple principal elements in equimolar or nearequimolar ratios $[1,2]$. Solid solution of many elements will tend to be more stable because of their large mixing entropies. High entropy alloys (HEA) are composed of at least 5 principal elements. Nowadays, unique structure and physical properties of HEA's are often subject of study. There are four main effects in HEA: thermodynamics - high entropy effect, kinetics — sluggish diffusion, structures - severe lattice distortion, and properties - cocktail effects [3]. Up to date, many HEAs with promising properties have been reported, e.g., high wear-resistant alloys, high-strength at room temperature or elevated temperatures, general corrosion resistance much better than conventional 304stainless steel [4]. FeSiBAlNi HEA system was inspired by $\mathrm{FeSiB}$ metallic glasses with good glass formation ability, thermal stability and soft magnetic properties. The amorphous high entropy alloys have been successfully fabricated using the mechanical alloying method. The as-milled FeSiBAlNi(Nb) powders are soft magnetic materials as it was published by Wang [5]. The Nb addition does not improve the soft magnetic properties

*corresponding author; e-mail: rbures@saske.sk of FeSiBAlNi HEA. FeSiBAlNi-Mo equiatomic high entropy alloy was prepared by mechanical milling. Influence of temperature-time regime of sintering process on properties of powder HEA was investigated.

\section{Experimental material and methods}

High entropy FeSiBAlNiMo alloy was prepared by mechanical alloying. Eqiatomic amount of $\mathrm{Fe} 99.8 \%$ (Höganäs $\mathrm{ABC}$ 100.30), Si 99.95\% (Sigma-Aldrich), B $95.00 \%$ (Sigma-Aldrich), Al 99.70\% (Praskovekovy, CZ), Ni $99.00 \%$ (GTV, Germany) and Mo $99.80 \%$ (Sigma-Aldrich) was dry milled in planetary ball mill Pulverisette6 (Fritsch, Germany), under protective Ar atmosphere (2 atm), for up to $336 \mathrm{~h}$ at $350 \mathrm{rpm}$. The steel milling vessel together with 1" steel balls in ball-topowder ratio of 14:1 were used. Prepared HEA was compacted by uniaxial cold pressing at pressure of $800 \mathrm{MPa}$ to the shape of square prism $4 \times 5 \times 20 \mathrm{~mm}^{2}$ of size. Green compact was sintered in tube furnace (Carbolite) in $\mathrm{Ar} / 10 \mathrm{H}_{2}$ atmosphere. Sintering temperatures from 480 to $1100^{\circ} \mathrm{C}$ and sintering time from 5 to $30 \mathrm{~min}$ were used.

Coercivity $\left(H_{c}\right)$ of green compacts and sintered samples was measured using Koerzimat HCJ 1.097 (Foerster). Elastic modulus $(E)$ was measured by impulse excitation technique using Buzz-o-sonic system (BuzzMac). Flexural strength was characterized by measurement of transverse rupture strength (TRS) using three point bending test on universal testing machine Tiaratest 2300 . Resistivity $(R)$ was measured by 4 point probe method using Loresta AX (Mitsubishi Chemical Analytech). Microstructure was observed using scanning electron microscope (SEM) JEOL JSM-7000F. X-ray powder 
diffraction (XRD) analysis was performed using X'Pert PRO (PANAnalytical) diffractometer with Co $K_{\alpha 1,2}$ radiation.

\section{Results and discussion}

Consolidation of cold pressed green bodies was performed by sintering at 480,530, 580, 630, 680, 730, 780, and $1100^{\circ} \mathrm{C}$ and dwell time $15 \mathrm{~min}$ to investigate influence of the sintering temperature on electro-magnetic and mechanical properties of the HEA.

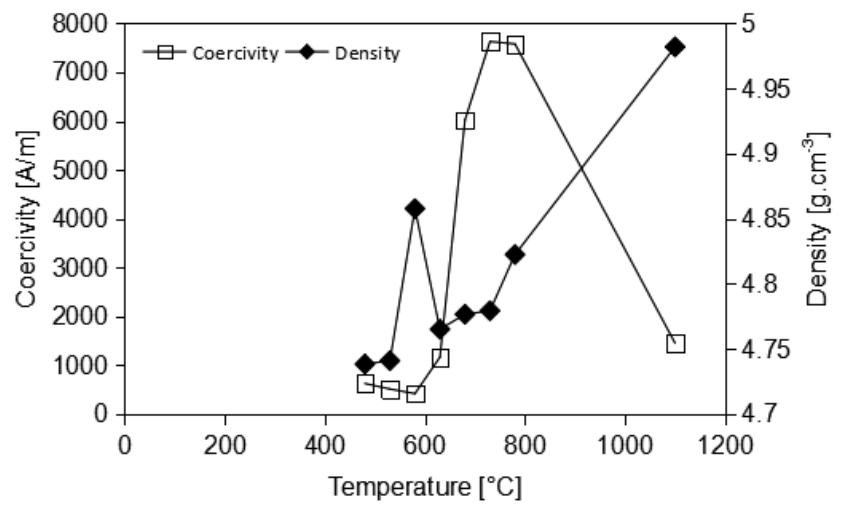

Fig. 1. Coercivity and density versus sintering temperature.

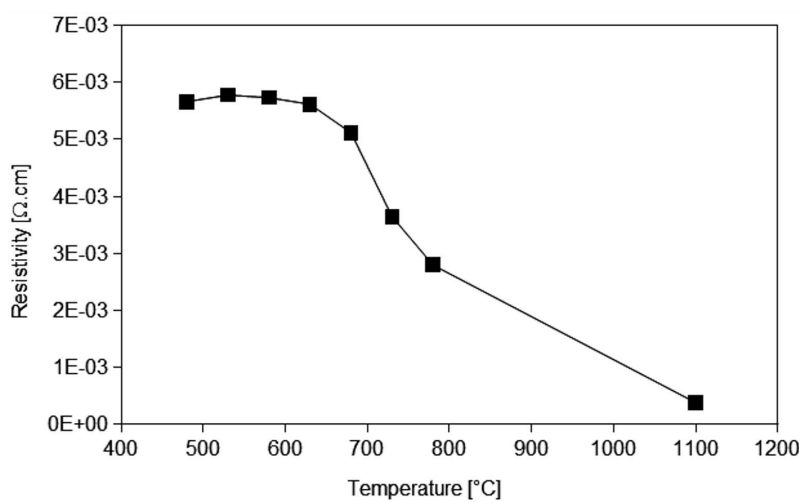

Fig. 2. Resistivity of sintered samples versus temperature.

Minimal value of coercivity $H_{c}=410 \mathrm{~A} / \mathrm{m}$ was achieved for sample sintered at $580^{\circ} \mathrm{C}$ while density achieved local maximum. Coercivity, in Fig. 1 increased with increase of sintering temperature up to $730^{\circ} \mathrm{C}$. Sintering temperature of $1100{ }^{\circ} \mathrm{C}$ led to $H_{c}=1450 \mathrm{~A} / \mathrm{m}$ and maximum density value $\rho=4.982 \mathrm{~g} \mathrm{~cm}^{-3}$.

Resistivity in Fig. 2 is near-to-constant up to $630^{\circ} \mathrm{C}$ and then decreases monotonously with increase of sintering temperature above $730^{\circ} \mathrm{C}$. Tendency of the Young modulus and flexural strength, in Fig. 3, was similar to resistivity. Theoretical melting temperature of the HEA calculated by JmatPro ver.8.0.5 based on alloy composition was $T_{m}=1370^{\circ} \mathrm{C}$. It is well known that sintering of the powders is performed at $0.7 T_{m}-0.8 T_{m}$. Temperature below $960^{\circ} \mathrm{C}$ is not enough for diffusion processes which

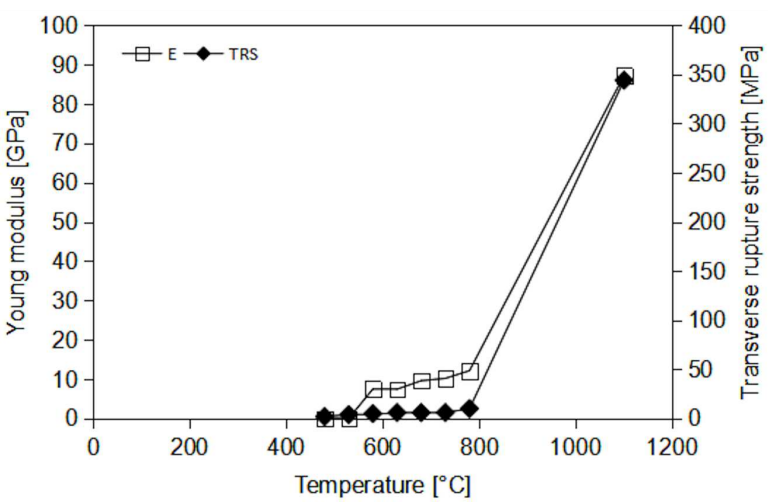

Fig. 3. The Young modulus $(E)$ and transverse rupture strength (TRS) versus sintering temperature.

lead to consolidation of the HEA powder. Mechanical properties rapidly increase after sintering at $1100^{\circ} \mathrm{C}$. However, the coercivity value was influenced by temperature below $0.7 T_{m}$ of HEA. Temperature about $580^{\circ} \mathrm{C}$ led to relaxation of residual stresses after mechanical alloying and cold pressing, which decrease the coercivity. Microstructure recovery without recrystallization could play important role also, as it is confirmed by density values in Fig. 1.

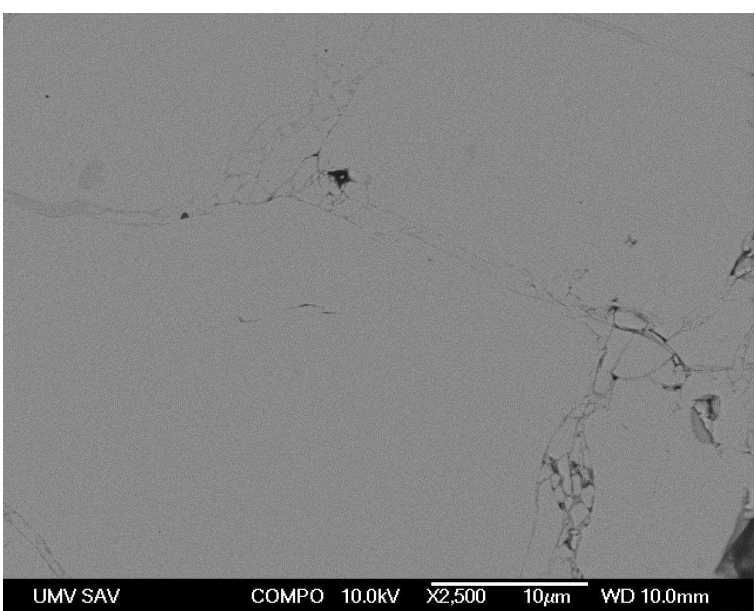

Fig. 4. Microstructure of HEA sintered at $580^{\circ} \mathrm{C}$, SEM.

Observation of the microstructure of HEA sample sintered at $580^{\circ} \mathrm{C}$, in Fig. 4 showed unsintered interparticle connections in contrast to sintering at $1100^{\circ} \mathrm{C}$, in Fig. 5 . High sintering temperature induced precipitation of borides.

Structure of sintered samples was investigated by XRD analysis. HEA sintered at $580^{\circ} \mathrm{C}$ consists of amorphous/nanocrystalline solid solutions with low far field ordering based on $\alpha$-Fe and AlNi as it is shown in Fig. 6 (bottom). Boride $\mathrm{Fe}_{0.375} \mathrm{Ni}_{0.375} \mathrm{~B}_{0.25}, \mathrm{Fe}_{3} \mathrm{Si}$ and complex boride based on (FeNiAlMo ${ }_{3} \mathrm{~B}_{2}$ precipitated at $1100^{\circ} \mathrm{C}$ of the sintering temperature as it is documented in Fig. 6 (top). 


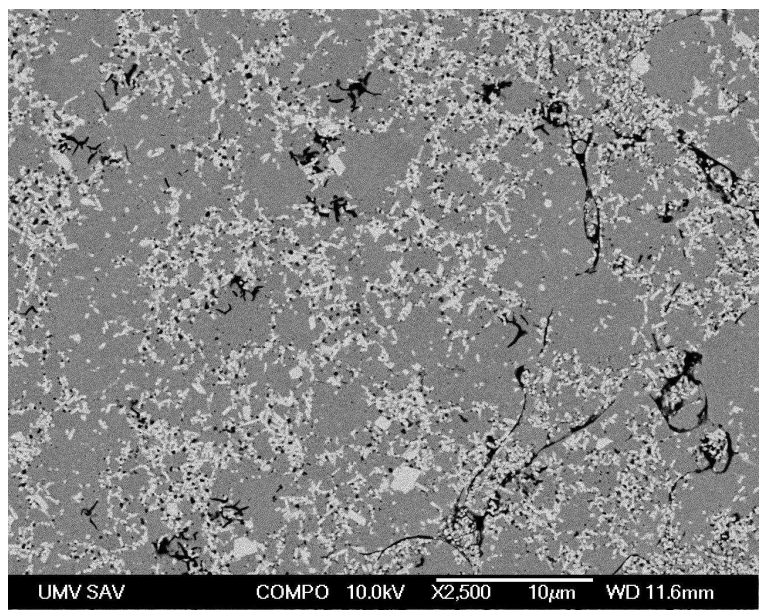

Fig. 5. Microstructure of HEA sintered at $1100^{\circ} \mathrm{C}$ SEM.

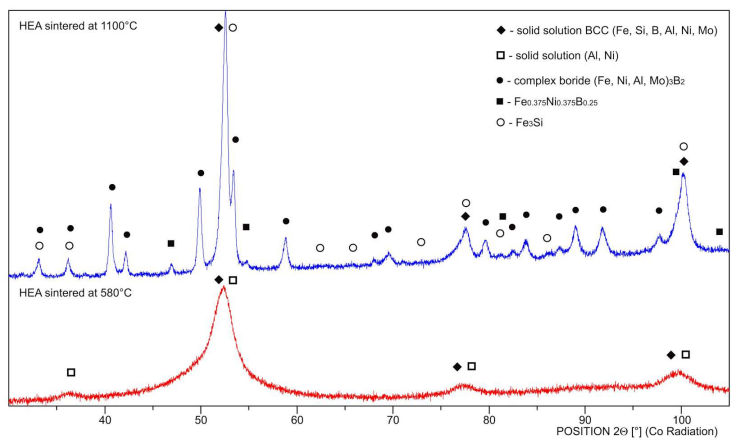

Fig. 6. X-ray patterns of $\mathrm{HEA}$ sintered at $580^{\circ} \mathrm{C}$ (bottom) and $1100{ }^{\circ} \mathrm{C}$ (top).

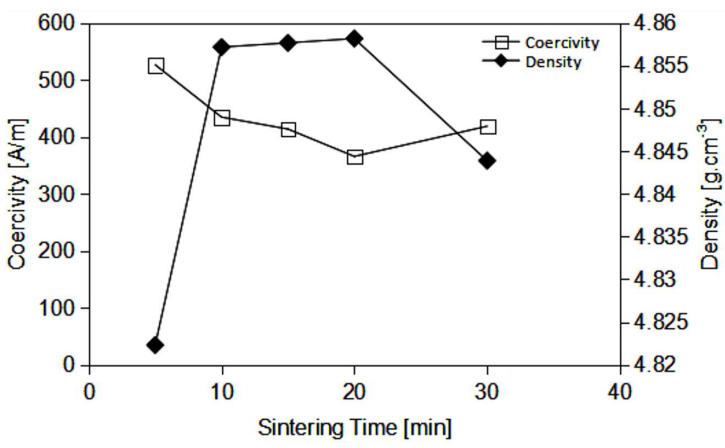

Fig. 7. Coercivity and density versus sintering time.

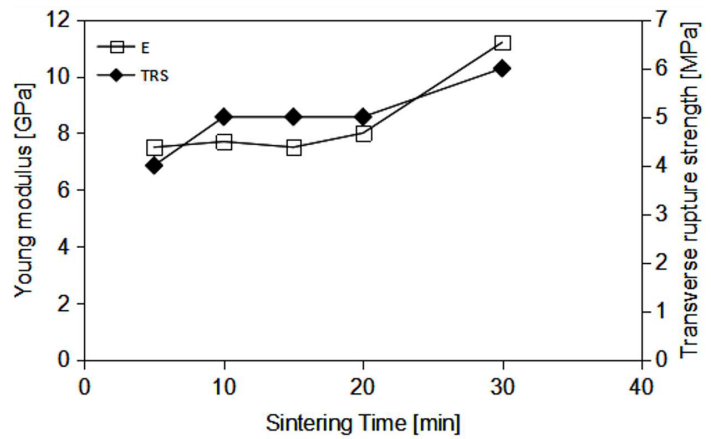

Fig. 8. The Young modulus $(E)$ and transverse rupture strength (TRS) versus sintering time.
Kinetics of the consolidation process was investigated by sintering at $T=580^{\circ} \mathrm{C}$ with dwell time $5,10,15,20$, and $30 \mathrm{~min}$. The lowest coercivity $H_{c}=370 \mathrm{~A} / \mathrm{m}$ was achieved by sintering for $20 \mathrm{~min}$. Prolonged sintering increases value of the coercivity and decreases density as it is shown in Fig. 7.

Values of the mechanical properties, in Fig. 8, confirmed that sintering at $580^{\circ} \mathrm{C}$ leads to low TRS even after 30 min of dwell time. A little higher increase was recorded in case of the Young modulus.

\section{Conclusions}

High entropy alloy FeSiBAlNiMo was prepared by mechanical alloying. Properties of HEA strongly depend on applied temperature and time regime of the sintering process. Stress relief heat treatment at low temperature leads to lower coercivity and relatively low mechanical strength. Structure of the HEA was mixed, amorphous and nanocrystalline. Flexural strength and the Young modulus were seven times higher in case of the HEA sintered at higher temperature at the cost of four times higher coercivity value. Properties of the sintered HEA were affected by formation of nanocrystalline complex borides.

\section{Acknowledgments}

This work was supported by the Scientific Grant Agency of the Ministry of Education, Science, Research and Sport of the Slovak Republic and the Slovak Academy of Sciences, project No. VEGA 2/0185/15 and by Czech Science Foundation project No. 14-25246S. This work was realized within the frame of the project "Advanced technology of preparing of micro-composite materials for electrotechnics", which is supported by the Operational Program "Research and Development" financed through European Regional Development Fund ITMS:26220220105.

\section{References}

[1] J.-W. Yeh, S.-K. Chen, S.-J. Lin, J.-Y. Gan, T.-S. Chin, T.-T. Shun, C.-H. Tsan, S.-Y. Chang, Adv. Eng. Mater. 6, 299 (2004).

[2] B.S. Murty, Jien-Wei Yeh, S. Ranganathan, HighEntropy Alloys, Elsevier, Oxford 2014.

[3] J.-W. Yeh, Europ. J. Control 31, 633 (2006).

[4] Y. Zhang, T.T. Zuo, Z. Tang, M.C. Gao, K.A. Dahmen, P.K. Liaw, Z.P. Lu, Prog. Mater. Sci. 61, 1 (2014).

[5] J. Wang, Z. Zheng, J. Xu, Y. Wang, J. Magn. Magn. Mater. 355, 58 (2014). 